\title{
PELOS SILÊNCIOS DAS TISANAS, DE ANA HATHERLY
}

Rodrigo da Costa Araujo

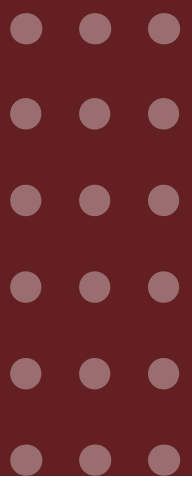


O poeta é um pintor do mundo invisível.

[ Hatherly ]

A poesia e a obra de arte, nos dinamismos que lhes são inerentes, instituem um espírito de crítica e um afã interpretativo, em busca de um redimensionamento de sua criatividade. O objetivo dessa crítica assume um questionamento da própria realidade que a obra/poesia procura representar e influenciar. Assim também são os traços delicados do livro de poesias Tisanas, da artista plástica, poeta, romancista, ensaísta e tradutora portuguesa, Ana Hatherly (1929-2015).

O questionamento ou a reflexão da própria obra no ato (discursivo ou literário) de criação é uma das características da atualidade, numa tentativa de ampliar as leis estéticas. É a própria crítica instaurada no mecanismo de sua escritura, como metáfora da realidade. Assim entende a própria Ana Hatherly, quando afirma, em Tisanas, de número 233:

O que há de impressionante na minha obra poética é o que nela há de recusa de expressão. O peso e o tamanho do que eu me recuso a exprimir eis o que eu digo-não-digo e finalmente digo (1997, p. 96-97).

Este fragmento-recado de Tisana, em tom de crítica e autocrítica, espécie de comando de leitura (para esse ensaio) e monólogo reflexão, auto inspeção dirigida aos leitores e críticos, certamente pode ser estendido a toda a sua obra. O leitor torna-se essa escuta e segue a trajetória do texto, deslizando em sua superfície. Terá de rejeitar a limitação de quem vive apenas do que é passível de fazer sentido. Da falta de sentido nasce a verdade inventada que tem a palavra como signo e jogo. Dessa recusa ou processo declarado, escrever/esconder é homólogo a ler.

A construção/confissão e recusa de Tisanas lançam aos olhos do leitor momentos, flashes fotográficos sobre de grandeza e asseveração vividos pelo sujeito poético. O texto se estrutura deixando na "recusa da expressão" leituras esquivas que tornam a teia semiótica textual pro- 
pensa a novos olhares. Os fragmentos parecem aportar e convocar o leitor para o movimento sutil dos deslocamentos, fluxos e comandos de leitura que forjam os passos do método de rastreamento da nova força, novo objeto, nova categoria. Esses comandos deixam latente um conjunto de pequenas relações que, por sua vez, permitem alguma conexão com poeta/poesia e leitor.

Conforme afirma o crítico Fernando J. B. Martinho, a escrita de Ana Hatherly não se segue à "compreensão e à apreensão da realidade", não visa "duplicar" ou "reproduzir" o mundo, mas antes "inventar, criar, 'produzir' outros mundos, acrescentar outros mundos ao mundo ('o que o mundo não tem/ o que o mundo não diz/ o que o mundo não é') ". (MARTINHO, 2004, p.49-50). O trabalho do poeta, reforça o crítico, é de "invenção ou de reinvenção", em vez de fabricar simulacros de um presumível 'real'; ou, conforme diz Martinho, nesta mesma passagem, citando versos de Ana Hatherly, o poeta "olha o mundo/ e reinventa-o/ no seu jardim feito de tinta" (pp. 49-50).

\section{A POÉTICA DO FRAGMENTO}

Além da metalinguagem, há ainda, nos poemas de Ana Hatherly e em Tisanas, a utilização do fragmento como processo crítico e marca da modernidade em busca de uma nova maneira de apresentação de sua arte poética. A fragmentação reforça certo comprometimento com o lirismo às avessas, pondo em evidência um mundo onde, nos voos da imaginação, articulam-se de modo ambíguo das palavras e desvios, aproximam-se em comunhão realidades distantes, diversificam-se dissonantemente o popular e o erudito, desencadeiam-se, caoticamente, novos entendimentos, sem se preocuparem com as amarras das normas gramaticais e da ordem estabelecida pelo pensamento lógico.

Para Latuf Isaias Mucci, quando teoriza o conceito de fragmento ressalta que ele é:

Testemunha do passado, que ajuda a compreender e a reconstituir, extrato de um livro, de um discurso, índice de uma crise do gênero, da totalidade, da obra, 
do sujeito, do autor e do leitor, espécie de gênero que engendrou uma estética do fragmento.[...] ele ressurge como signo de certa modernidade em busca de uma nova linguagem num mundo onde a unidade e a certeza não são, definitivamente, evidentes onde vigem a aporia, as contradições, a fluidez, inscritas, como modos de dispersão e justaposição, no texto.

Acompanhando esse raciocínio, Tisanas é construído por fragmentos, de articulações de instantes que vêm picar, ferir, como o punctum barthesiano ${ }^{1}$ o leitor, no momento de ler, desmontando uma estética da descrição da vida em proveito do imaginário da escritura. A poeta-esteta, nesse sentido, reflete, em suas múltiplas máscaras e rubricas, e na polifonia de suas referências artísticas e culturais, uma marca singular em relação ao discurso poético. É a singularidade desse discurso, o registro do cotidiano e as miríades de conexões por ele viabilizadas que pluralizam a leitura das descobertas.

O fragmento, portanto, marca inconfundivelmente da poética hatherliana, presta-se em alto grau ao objetivo da autora, o de escapar à organização retórica, o que equivale a dizer, dada a explicitação desse objetivo, que o autor não tem ensinamentos a transmitir e tampouco tem a pretensão de criar, com sua produção literária, um modelo que possa ser seguido ou imitado. Isso se comprova tanto pela pluralidade de sua obra como um todo, quanto pelo fato de dela não se poder extrair nenhuma metodologia aplicável ao tratamento dos textos. Assim, a pluralidade do autor espelha a pluralidade do leitor e, essa relação especular está na própria raiz do conceito de poesia que nasce desse processo.

Em Tisanas, os fragmentos exibem-se como espetáculo das impressões dos acontecimentos, dos testemunhos literários e poéticos, da observação minuciosa, do cotidiano e da vida pessoal, transcritas, inscritas, reescritas nesse livro. A estética do fragmento, para Latuf Isaias Mucci, recria um "espaço literário", postulado por Maurice Blan-

1 Punctum é mais conhecido como um conceito de Roland Barthes, o que em fotografia "pinça o olhar do espectador". A definição de punctum em fotografia, segundo Barthes (1984, p. 45-46), é um despertar para algo que nos chamou a atenção na imagem. Esse despertar - ao contrário do studium que é do leitor para imagem o interesse ou o gosto pela foto - emana da cena na fotografia para o leitor e é parecido com uma marca que pontua, um instrumento que fere. 
chot (1907-2003), em que cintilam, significam, reverberam resíduos, traços, marcas discursivas. Dele, resulta um relativismo estético e histórico, que amalgama o criador e o leitor, no desenho da rede escritural, onde bailam os objetos percebidos, os signos lidos, relidos, interpretados e reinterpretados. As Tisanas, segundo a própria Hatherly em uma entrevista:

[...] são ligadas aos Sonhos, mas ao contrário. Os Sonhos e as Tisanas são parecidos porque é a mesma pessoa que os escreve. As origens das Tisanas é o Budismo Zen. São em parte inspiradas nas fábulas dos Mestres Zen. Mas também são uma espécie de fábulas ou anti-fábulas que eu invento. $\mathrm{O}$ estilo Zen tinha como função o desalojar as pessoas do hábito. Era para criar perplexidade. [...] Criar a perplexidade é tirar o tapete debaixo das pessoas, retirar as certezas. (HATHERLY apud ROSENGARTEN. 2004. p.120).

Na poética hatherliana, tornam-se evidente esse pensamento e a problematização da chamada "lógica", características de um determinado discurso e uma maneira de pensar. Os fragmentos e sua brevidade correspondem à revelação de uma liberdade como recorrência à sua própria poética, onde os poemas são construídos por conexões de fragmentos, como um brinquedo de montar, passível de decomposição e recomposição. Apesar dessas transformações, "a composição fragmentária tende assustar os leitores que estão habituados a imagens e estilos tradicionais" (ROSENTHAL, 1975, p. 156).

Segundo Osmar Calabrese, como, também, Latuf Isaias Mucci, as novas tecnologias propõem ao leitor hoje maneiras renovadas de compreender o pormenor e o fragmento, sobretudo nos meios de comunicação social. É desse modo que Calabrese reforça: "observar o (ou os) critérios de pertinência segundo os quais se opera por pormenores ou por fragmentos pode dizer-nos algo acerca de um gosto no estabelecimento de estratégias textuais, quer de gênero descritivo, quer criativo" (1988, p. 84). O fragmento, explica Calabrese em A Idade Neobarroca (1988) deriva do latim frangere e significa quebrar. Para ele, "o fragmento pressupõe, mais do que o sujeito romper-se, o seu objecto" (1988, p. 88). O fragmento, embora fazendo parte de um inteiro anterior, não contempla, para ser definido, a sua presença. Nesse caso, “o inteiro está in 
absentia". A geometria do fragmento ensina Calabrese, "é a de uma ruptura em que as linhas de fronteira devem considerar-se como motivadas por forças [...] que produziram o "incidente" que isolou o fragmento do seu todo de pertença" (1988, p. 88). É a partir dessa noção que o autor caracteriza o fragmento como parte de uma obra de re-construção de um sistema, ao contrário do detalhe que produz uma obra de re-constituição. O fragmento é, de modo geral, "uma porção presente que reenvia para um sistema suposto como ausente" (1988, p. 90).

Da colisão entre os fragmentos em Tisanas, surgem as centelhas do poético, os sortilégios da poesia. O procedimento da poeta desorganiza o código comum, cria obstáculos ou deslocamentos para a leitura, estabelecendo novas relações entre as palavras que privilegiam o novo e instauram uma linguagem ambígua, precária e evanescente, enraizada na desestabilização do sentido. Portanto, reforçando a fragmentação, a linguagem poética em Ana Hatherly, ao criar novas hierarquias, faz aumentar a dificuldade da percepção, levando o leitor a ter acesso ao desconhecido, singularizando a visão das coisas, que, pelas suas rupturas, $o$ verso não se completa sintática e semanticamente.

\section{SILÊNCIO, DESLOCAMENTO E ESCRITURA}

À primeira vista, de um lance de leitura, Tisanas (1998), de Ana Hatherly pode soar como um aglomerado de não senso e aleatoriedade, recortes agrupados ao acaso, uma verdadeira escrita sem rumo e perturbante, ou automática, semelhante aos exercícios surrealistas:

O transparente opaco é um lago de pedra em que o peixe é a água que se agita de um lado para o outro embatendo sempre nas paredes duras. Que importa que seja a parede? Todo o muro é angústia, toda água aflição (HATHERLY, 1988, p. 78), pois

um modo de escrever pouco apegado à clareza, à justeza do significado. Uma aparente pouca preocupação em expor informações, explicar, significar. Um culto ao hermetismo? Um jogo de esconde-esconde, uma grande brincadeira? De qualquer modo, em sua literatura o que chama a atenção e valoriza sobre- 
modo sua poética é a ousadia em penetrar em universos complexos (da leitura e da visualidade) e já bastante saturado pelas mídias e pela leitura, para, a partir daí propor um novo e diferente olhar, no qual a poesia e a imagem leiam e passam a ser lidas, numa interação que desestabiliza a inércia dos sentidos.

Hibridismo de gêneros, ironia, concisão, confissões e cotidiano são temas e estratégias das tisanas que se apropriam de formas clássicas (conto de fadas, fábulas, crônicas etc) para inovarem e transgredirem. De fato, o leitor, também à deriva, percebe-se, e aceita essa proposta, diante de fragmentos que não se totalizam. Há em Ana Hatherly uma curiosa colagem de pedaços que parecem extraídos de universos totalmente disparatados. São lugares, viagens, confissões e paisagens distantes que coexistem em um mesmo texto, como se o leitor tivesse de juntar peças para montar um quebra-cabeças. A própria poeta, a respeito das suas Tisanas, disse:

[...] Tisanas são infusões, ora, a infusão é o contrário da efusão, portanto, a infusão aponta para dentro e não para fora. Há uma profunda meditação, é realmente um trabalho de filosofia, uma obra aberta (no sentido actual mas também Barroco do termo), que eu não considero nunca terminada. Só termina com a minha morte, porque no fundo é a minha vivência mais secreta, mais profunda, e talvez seja isso o que atrai as pessoas. Há qualquer coisa de profundamento humano, doloroso e ao mesmo tempo exaltante da existência, que às vezes transparece em algumas Tisanas. Eu penso que seja isso, mas nunca se sabe porque é que as pessoas gostam de um texto! (HATHERLY apud MARTINHO, 2004. p. 133).

Diante de tal plano, repleto de direções, temas, tons, impressões, cores, imagens só se pode encontrar a unidade do fragmentário, uma espécie de unidade múltipla de si, incapaz de amalgamar, ou fundir suas partes. Das incursões pelos fragmentos, fica a sensação de resumo, estratégia que condensa as influências estético-literárias da produção literária e artística da autora. Flanando, o leitor busca nas peças do quebra-cabeças recortes distintos, que trazem cada uma, um pequeno fragmento de um mundo estrangeiro.

Todos os assuntos referidos e elencados nas Tisanas são organizados em séries, desiguais, assistemáticas, feitos cenas desmontadas, despedaçadas. Diferentemente do esperado, os fragmentos não se oferecem 
como espécie de "guia" para a leitura, porque exploram o inesperado, delineiam um modo particular de como a autora lida com a linguagem. Desse modo, cada leitura dessas peças seria um povoamento singular, um arranjo único de séries. Mas para se chegar a isto, é certo que o ato de leitura deve ser concebido como sendo, por natureza, sempre um processo de atualização, de releitura, de intertextualidade ou reinvenção.

Além dessas atualizações das leituras e das tisanas, agrega-se a isso, o que Pinharanda constata sobre o desparecimento dos territórios entre escrita e visualidade, entre literatura e artes plásticas. Esse processo implica não somente uma reinvenção da leitura, da poesia e das tisanas. A escrita, contudo, continua a ser matriz do traço, o lugar a partir do qual é possível entrever desdobramentos e intersecções, como a pintura continua a ser, também, o gesto originário da escrita, tendo em vista que:

[...] Ana Hatherly insiste na negação de um tradicional estatuto artístico, quer para sua obra quer para si mesma. As dúvidas sobre o estatuto das obras e da sua autora deixam-nos com dificuldades de territorialização, quer da própria obra quer do seu significado, ou seja, sem capacidade para estruturar nem qualquer sistema e discurso críticos as modalidades sob as quais devemos assimilar/integrar, em nós, a nossa própria leitura dessas imagens (PINHARANDA, 2003, p. 11).

Na leitura sobre a renovação da poesia portuguesa contemporânea, Rosa Maria Martelo (2014) ressalta como os koans japoneses contribuíram como uma referência e um modelo de escrita inovadores. Para a pesquisadora portuguesa, Tisanas, de Ana Hatherly explora a mesma consciência da "indeterminação deslizante" do sentido que os koans amplamente exemplificam em consonância com o pensamento Zen. Na brevidade dos fragmentos e pelo frescor dos koans, a linguagem registra a marca da experiência imediata da vida, do registro do cotidiano em estado bruto.

Dos deslizes e deslocamentos dos sentidos, do ar despretensioso, surge na Tisana 275, a seguinte indagação: "Voltemos ao Koan. O que é o sentido? Uma mala fechada que nunca teve fecho. Eis a ironia da hu- 
mildade", 1988, p.70). Dessa pergunta-reflexão e resposta irônica, surge a presença de um procedimento que revela os traços de um novo tipo de relação com a escrita e com a literatura, agora quase confundida com a vida e as viagens. Por isso mesmo, pode-se considerar o koan como um mecanismo que, em suas sutilezas, proporciona uma pluralidade de rotas de leitura e de construção de significados, e não apenas a uma única via interpretativa das poesias e dos fragmentos.

\section{CONCLUSÃO}

Ao produzir leituras dialógicas entre artes plásticas e poesia/fragmentos pretende-se ampliar o conceito de leitura, redimensionar a função do sujeito-leitor, dinamizar as formas de aquisição dos conhecimentos literários e percorrer um viés interdisciplinar/semiótico. A poesia de Ana Hatherly instiga isso e opera como que em blocos estanques; de repente quebra-se um ritmo e se imobiliza numa fotografia o lugar onde decorre a ação. Assim, tem-se a absolutização da imediatez da imagem, que se move de maneira totalmente diferente da imediatez da palavra. Pode-se mesmo dizer que, em algumas poesias ou fragmentos dela, o despojamento da linguagem atinge, muitas vezes, um ponto em que há apenas uma sequência de "tomadas" em série. Nada se descreve além da ação ou da continuidade delas; a enumeração caótica registra apenas fragmentos de discursos, vestígios de paisagens, traços de corpos ou rostos fugidios. Aproxima-se de um estilo imagético, visceralmente ligado à linguagem cinematográfica e televisiva.

O grande jogo das Tisanas, de Ana Hatherly parece apontar para um texto que explicita a descontinuidade de sua construção, deixando pontas soltas, bifurcações, espaços para o leitor completar na/com atualização de sua leitura. Mesmo provocando deslocamentos e visualidades, a sensação que fica é que as virtualidades já estão nos fragmentos, presentes e reais no plano de suas composições, independentes de qualquer realidade externa. Essas virtualidades pertencem à própria materialidade do texto e é ali que guardam para serem atualizadas. 
Trajeto ou percurso discursivo de quem mais se interroga do que responde, as Tisanas, de Ana Hatherly traçam os diversos retratos por que a vida se estende e misteriosamente se cruza e se interpenetra; a nenhum deles é alheia a obsessiva procura de encontros: da poeta consigo mesma, da poeta com as outras artes, com a escrita, com o mundo e com aspectos da sua convivência.

\section{REFERÊNCIAS}

ARAUJO, Rodrigo da C. Caligrafias e escrituras de Ana Hatherly. Belo Horizonte. Caravana.2021.

BARTHES, Roland. Le plaisir du texte. Paris. Seuil. 1977.

_. A Câmera Clara: nota sobre a fotografia. Rio de Janeiro. Nova Fronteira. 1984.

CALABRESE, Omar. A Idade Neobarroca. Lisboa. Edições 70.1988.

HATHERLY, Ana. Fibrilações. Lisboa. Quimera 2005.

_. A Cidade das Palavras. Lisboa. Quetzal. 1988.

_. 351 Tisanas. Coimbra. Quimera.1997.

_.463 Tisanas. Lisboa: Quimera. 2006.

_. A idade da escrita e outros poemas. São Paulo. Escrituras Editora. 2005.

- Interfaces do olhar - uma antologia crítica/uma antologia poética. Lisboa: Roma Editora, 2004.

_. O espaço crítico - do Simbolismo à vanguarda. Editorial Caminho. Lisboa. 1979.

MARTINHO, Fernando J. B. Entrevista a Ana Hatherly In: HATHERLY, A. Interfaces do olhar: uma antologia crítica, uma antologia poética. Lisboa: Roma, 2004, p. 129-138.

MARTELO, Rosa Maria. Os Koans Revisitados (Ou de como Escrever 
entre Poesia e Prosa). In: eLyra, n. 4, p.15, out., 2014. Disponível em: $<$ http://www.elyra.org/index.php/elyra/article/view/55>. Acesso em: 6 jun. 2021.

MUCCI, Latuf Isaias. Fragmento. "Verbete", E-Dicionário de Termos Literários, coord. de Carlos Ceia. Disponível em: <http://www.fcsh.unl.pt/ edtl>. Acesso em: 22-01-2021.

PAZ, Octavio. Signos em rotação. São Paulo. Perspectiva. 2005.

PINHARANDA, João Lima. "Imagem-Acção" In: HATHERLY, A. A mão inteligente. Lisboa: Quimera, 2003, p. 11-17.

ROSENGARTEN, Ruth. Queda livre. In: HATHERLY, A. Interfaces do olhar - uma antologia crítica/ uma antologia poética. Lisboa: Roma Editora, 2004, p. 115-123.

ROSENTHAL, E. Theodor. O universo fragmentário. USP. São Paulo. Cia Editora Nacional. 1975. 